\title{
XXXIII. MERCURIALIS.
}

\section{THE DEVELOPMENT OF A BLUE PIGMENT ON DRYING.}

\author{
By PAUL HAAS aNd THOMAS GEORGE HILL. \\ From the Botanical Department of University College, London.
}

(Received February 25th, 1925.)

IT has long been known that the green shoots of Mercurialis perennis and $M$. annua acquire a bluish hue on drying, a fact that is perhaps not as widely known to botanists as might be expected. The only reference to the nature of the blue pigment which we have been able to trace is one by Molisch [1893], who, in the course of a systematic search for indigo-producing plants examined $M$. perennis and dismissed this plant with the remark that the pigment is not indigo, since it is turned red by the addition of acid.

With regard to the mechanism of the production of the blue colour the possibility of enzyme action at once suggests itself since, in a great many cases, the post-mortem coloration of vegetable tissue has been shown to be due to the presence either of an oxidase acting upon some constituent of the substrate or of a hydrolytic enzyme acting upon a glucoside, as has been shown by Bridel and Braecke [1922, Bridel, 1923] for Melampyrum, Monotropa and other plants.

In the present instance of Mercurialis, however, it would appear from our observations that enzyme action of any kind is highly improbable. The possibility of oxidase action is excluded since this plant does not contain a direct acting oxidase but only a peroxidase which is incapable of exerting its activity until after the addition of a peroxide. The possibility of other enzyme action is unlikely in view of the fact that the blue pigment can be produced by drying the tissues after such treatment as immersion in boiling water or suspension in steam; further the pigment may be produced by leaving the tissues to soak for some time in absolute alcohol, a reagent which is not generally regarded as favourable for enzyme action. Our observations lead us to conclude that desiccation is the prime factor concerned in the production of this blue pigment.

\section{The Preparation of the Blue Pigment by Desiccation.}

(a) By the use of absolute alcohol. This reagent, as is well known, rapidly removes water from fresh tissues and also quickly expels the air contained within the intercellular space system of the plant, a point of some importance 
in view of the formation of another blue pigment by oxidation. The use of absolute alcohol enables one either to extract the blue pigment or, by slightly modifying the conditions, to bring about its deposition within the tissues. If the former be desired it is necessary to use the colourless rhizomes in order to avoid contamination with chlorophyll. The freshly-gathered rhizomes are washed free from adhering soil, dried with a cloth, rapidly cut up into short lengths and dropped into absolute alcohol contained in a flask; the latter is then gently warmed over a water-bath to a temperature not exceeding $40^{\circ}$. The resulting deep blue solution is filtered into a distillation flask and evaporated to small bulk under reduced pressure in a stream of nitrogen. The residual liquid consists of a violet coloured aqueous solution in which is suspended a flocculent greyish white substance, which on filtration and exposure to air darkens. This material contains phosphorus, and from its solubilities and general behaviour, appears to be of a lecithin-like nature, but it has not as yet been fully investigated. The aqueous filtrate on evaporation to dryness yields a dark blue material which sets to a brittle varnish.

If it is desired to produce the pigment in the tissues and to leave it there deposited with a view to studying its anatomical distribution, advantage may be taken of the circumstance that the pigment is insoluble in absolute alcohol and only comes out into solution if the alcohol is allowed to become diluted by the moisture withdrawn from the tissues. To study the distribution in green leaves or shoots it is therefore necessary to immerse them in absolute alcohol and to replace the alcohol frequently, as it takes up moisture from the tissues; in these circumstances only the chlorophyll goes into solution and the alcohol is accordingly coloured green and not blue. If such an experiment is carried out successfully the tissues gradually lose all their chlorophyll and assume an intense azure blue colour. The blue pigment can be removed from such tissues by immersion in water.

(b) By drying. In the early phases of this investigation it was observed that on drying the material developed the blue pigment very irregularly. In order to discover the best method, green shoots and leaves and colourless rhizomes were dried under a great variety of conditions, as a result of which it was found that the best yield of blue is obtained by drying as slowly as possible, in a dark cool place. Under these conditions of slow drying there is less tendency for the production of the unstable and readily oxidisable blue compound to be described later; the choice of a dark place is to be recommended more particularly in the case of green material, since there is less danger of contamination with possible degradation products of chlorophyll.

To extract the pigment from the tissues, the dried material is ground in a mill and a quantity of the resulting powder is stirred into cold water until the powder is thoroughly wet. The pigment rapidly diffuses out and the extraction is complete in half an hour, if the paste is kept well stirred. The material is then placed in a linen bag and expressed in a tincture press. The greenish-blue liquid thus obtained may be used for extracting a fresh quantity of the powder 
and by so doing a strong solution results. This is centrifuged and, if necessary, filtered.

Reference has already been made to the production, by oxidation; of a second blue compound which on further oxidation gives a yellow one. There is good reason to infer, as will be seen later, that both these blue compounds are produced from the same mother substance and that if the chromogen is converted into the transient blue compound it cannot form the permanent blue substance.

It is the production of the yellow substance, in varying amount, which is responsible for the fact that in a length of dried rhizome a portion may be yellow while the rest is peacock blue. The yellow compound being likewise soluble in water is extracted together with the permanent blue and is thus responsible for the peacock green colour of the extract. To remove this impurity, the centrifuged solution is saturated with ammonium sulphate, whereby the blue compound is precipitated; the filtrate, which contains the yellow compound together with a small additional quantity of the blue, is bright green in colour; on prolonged standing a little more of the blue compound is thrown out. The precipitated pigment is filtered off, washed with saturated ammonium sulphate solution and dried at $37^{\circ}$. The chemical properties of this substance are still under investigation.

\section{Distribution of the Blue Pigment.}

All parts of the dried plant, aerial shoots and subterranean rhizomes and roots, may show a peacock blue coloration, which appears in the last phases of desiccation, the colour being densest in the younger parts. Thus the apex of the shoot contains more pigment than the basal region, young leaves contain more than old, young white rhizomes are much richer than the older brown. In axial structures the pigment is restricted to the cortical parenchyma and in the leaves it is distributed more or less evenly throughout the parenchyma of the mesophyll.

\section{SUMMARY.}

1. There exists in Mercurialis a chromogen which gives rise to a blue pigment on drying.

2. The production of the blue colour is not due to enzyme action.

3. Methods are described for the isolation of the pigment.

4. The yield of the pigment indicates that the chromogen is most abundant in the youngest and vigorously growing parts.

\section{REFERENCES.}

Bridel (1923). Bull. Soc. Chim. Biol. 5, 722.

- and Braecke (1922). Bull. Soc. Chim. Biol. 4, 96.

Molisch (1893). Sitzungsber. kais. Akad. Wiss. Wien. 102 (1), 269. 